\title{
A composite iterative algorithm for accretive and nonexpansive operators
}

\author{
Hengjun Zhao \\ School of Science, Henan University of Engineering, Zhengzhou 451191, China.
}

Communicated by $\mathrm{X}$. Qin

\begin{abstract}
In this paper, we propose a one-step composite iterative algorithm for solving operator equations involving accretive and nonexpansive operators. We obtain a weak convergence theorem for these nonlinear operators in the framework of 2-uniformly smooth and uniformly convex Banach space. (C)2017 All rights reserved.
\end{abstract}

Keywords: Accretive operator, nonexpansive operator, uniformly smooth, zero point. 2010 MSC: 47H06, 47H09, 90C33.

\section{Introduction and preliminaries}

The iterative construction of solutions to accretive or monotone operator equations, which is a cross research field between nonlinear functional analysis and the optimization theory, finds a lot of applications in pure and applied sciences; see $[1,9,10,15]$ and the references therein.

There are a substantial number of numerical methods including projection methods and its variant forms, auxiliary principle, Wiener-Hopf equations, and descent for solving accretive or monotone operator equations. It is well-known that the projection methods, Wiener-Hopf equations techniques, and auxiliary principle techniques cannot be extended and modified for solving variational inclusion problems of multivalued monotone operators. This fact motivates to develop another efficient technique, which involves the use of the resolvent operator associated with m-accretive or maximal monotone operators. For the technique of resolvent operator, which is recently investigated by many authors; see [7, 13, 17] and the references therein, we can solve accretive or monotone operator equations via fixed point algorithms.

A Banach space $E$ is said to be uniformly convex if for each $\delta>0$ there is an $\epsilon>0$ such that, $\forall x, y \in E$ with $\|x\| \leqslant 1,\|y\| \leqslant 1,\|x+y\| \leqslant 2-2 \epsilon$ and $\|x-y\| \geqslant \delta$ hold. The modulus of convexity of $E$ is defined by

$$
\epsilon^{\mathrm{E}}(\delta)=\inf \left\{1-\left\|\frac{x+y}{2}\right\|:\|x-y\| \geqslant \delta,\|x\| \leqslant 1,\|y\| \leqslant 1\right\}, \forall \delta \in[0,2] .
$$

$\mathrm{E}$ is said to be uniformly convex if $\epsilon^{\mathrm{E}}(0)=0$, and $\epsilon(\delta)>0$ for all $0<\delta \leqslant 2$. It is known that a Hilbert space is 2 -uniformly convex, while $L_{p}$ is $\max \{2, p\}$-uniformly convex for every $p>1$.

Email address: zzzhaohj@outlook.com (Hengjun Zhao)

doi:10.22436/jnsa.010.06.10 
Let $S_{E}=\{x \in E:\|x\|=1\}$. E is said to be smooth or said to be have a Gâteaux differentiable norm iff the limit

$$
\lim _{t \rightarrow 0}(\|x+t y\|-\|x\|) / t
$$

exists for each $x, y \in S_{E}$. $E$ is said to have a uniformly Gâteaux differentiable norm if for each $y \in U_{E}$, the limit is attained uniformly for all $x \in S_{\mathrm{E}}$. $E$ is said to be uniformly smooth or said to have a uniformly Fréchet differentiable norm if the limit is attained uniformly for $x, y \in S_{E}$.

Let $\rho(E):[0,1) \rightarrow[0,1)$ be the modulus of smoothness of $E$ defined by

$$
\rho(E)_{t}=\sup \left\{\frac{\|x+y\|+\|x-y\|-2}{2}: x \in S_{E},\|y\| \leqslant t\right\} .
$$

A Banach space $E$ is said to be uniform smoothness if $\rho(E)(t) \rightarrow 0$ as $t \rightarrow 0$. Let $q>1$. A Banach space $E$ is said to be $q$-uniform smoothness, if there exists a fixed constant $c>0$ such that $\rho(E)(t) \leqslant c t^{q}$. It is well-known that $E$ is uniform smoothness iff the norm of $E$ is uniformly Fréchet differentiable. If $E$ is a q-uniform smoothness Banach space, then $q \leqslant 2$ and $E$ is uniformly smooth, and hence the norm of $E$ is uniformly Fréchet differentiable, in particular, the norm of $E$ is Fréchet differentiable. Typical examples of both uniformly convex and uniformly smooth Banach spaces are $L_{p}$, where $p>1$. More precisely, $L_{p}$ is $\min \{p, 2\}$-uniformly smooth for $p>1$.

Given of strictly increasing continuous real function: $\varphi: R^{+} \rightarrow R^{+}$, where $R^{+}$denotes the set of nonnegative real numbers, such that $\varphi(0)=0$ and $\lim _{\mathrm{r} \rightarrow \infty} \varphi(\mathrm{r})=\infty$, we associate with it a duality map $\mathfrak{J}_{\varphi}: \mathrm{E} \rightarrow 2^{\mathrm{E}^{*}}$, defined as

$$
\mathfrak{J}_{\varphi}(x):=\left\{x^{*} \in \mathrm{E}^{*}:\left\langle x, x^{*}\right\rangle=\varphi(\|x\|)\|x\|,\left\|x^{*}\right\|=\varphi(\|x\|)\right\}, \quad \forall x \in E,
$$

where $\langle\cdot, \cdot\rangle$ denotes the generalized duality pairing between $E$ and $E^{*}$. In the case that $\varphi(x)=x$, we write $\mathfrak{J}$ for $\mathfrak{J}_{\varphi}$ and call $\mathfrak{J}$ the normalized duality mapping.

Let $T: E \rightarrow E$ be a mapping. We use Fix $(T)$ to denote the fixed point of $T$. Recall that $T$ is said to be nonexpansive iff

$$
\|T x-T y\| \leqslant\|x-y\|, \quad \forall x, y \in C .
$$

Recently, fixed point theory of nonexpansive mappings has been applied to the variational inclusion problem of accretive or monotone operators; see $[3,16,24]$ and the references therein.

The basic idea is to reduce inclusion problems to fixed point problems of nonexpansive operators, which is initially investigated in the work of Browder [5]. Rockafellar [21] introduced this iterative algorithm and called it the proximal point algorithm, which is now recognized as the Rockafellar's proximal point algorithm: for any initial point $x_{0} \in H$, a sequence $\left\{x_{n}\right\}$ is generated by $x_{n+1}=\left(I+r_{n} A\right)^{-1}\left(e_{n}+x_{n}\right)$, $\forall n \geqslant 0$, where $A$ is a accretive operator, $\left\{r_{n}\right\}$ is a positive real number sequence and $\left\{e_{n}\right\}$ is an error sequence. He proved the weak convergence of sequence $\left\{x_{n}\right\}$ under appropriate restrictions imposed on $\left\{r_{n}\right\}$. To find the strong convergence, Bruck [6] proposed the following algorithm: for any initial point $x_{0} \in \mathrm{H}$ and fixed point $u \in H, x_{n+1}=\left(I+r_{n} A\right)^{-1} u, \forall n \geqslant 0$. He proved the strong convergence of sequence $\left\{x_{n}\right\}$ under appropriate restrictions imposed on $\left\{r_{n}\right\}$. In the case of $A=S+T$, where $S$ and $T$ are accretive operators, splitting algorithms have recently been investigated for solving inclusion problems; see $[2,8,11,18]$ and the references therein. These algorithms in the framework of Hilbert spaces are based on the good properties of resolvent operators, but these properties are not available in the framework of general Banach spaces; see [20] and the references therein. It is our aim to establish convergence theorems for two accretive operators via a fixed point method of a nonexpansive mapping.

Let I denote the identity operator on $E$. An operator $A \subset E \times E$ with domain $D(A)=\{z \in E: A z \neq \emptyset\}$ and range $R(A)=\cup\{A z: z \in D(A)\}$ is said to be accretive iff, for $t>0$ and $x, y \in D(A)$,

$$
\|x-y\| \leqslant\|x-y+t u-t v\|, \quad \forall u \in A x, v \in A y .
$$

Kato [14] proved that $A$ is accretive iff, for $x, y \in D(A)$, there exists $\mathfrak{j}_{\mathbf{q}}\left(x_{1}-x_{2}\right)$ such that $\left\langle u-v, j_{q}(x-y)\right\rangle \geqslant$ 0 . An accretive operator $A$ is said to be $m$-accretive iff $\operatorname{Ran}(r A+I)=E$ for all $r>0$. 
Recall that a single-valued operator $A: E \rightarrow E$ is said to be $\alpha$-inverse strongly accretive if there exists a constant $\alpha>0$ and some $\mathfrak{j}(x-y) \in \mathfrak{J}(x-y)$ such that

$$
\alpha\|A x-A y\|^{2} \leqslant\langle A x-A y, j(x-y)\rangle, \quad \forall x, y \in E .
$$

For an accretive operator $A$, we can define a nonexpansive single-valued mapping $J_{r}^{A}: \operatorname{Ran}(I+r A) \rightarrow$ $\operatorname{Dom}(A)$ by $J_{r}^{A}=(I+r A)^{-1}$ for each $r>0$, which is called the resolvent of $A$. In a real Hilbert space, an operator $A$ is m-accretive iff $A$ is maximal monotone. In this paper, we use $A^{-1}(0)$ to denote the set of zeros of $A$.

Lemma 1.1 ([19]). Let $\mathrm{E}$ be a real Banach space and let $\mathrm{C}$ be a nonempty closed and convex subset of $\mathrm{E}$. Let $\mathrm{B}: \mathrm{E} \rightarrow 2^{\mathrm{E}}$ be an $\mathrm{m}$-accretive operator and let $\mathrm{A}: \mathrm{C} \rightarrow \mathrm{E}$ be a single-valued operator. Then

$$
\operatorname{Fix}\left((I+r B)^{-1}(I-r A)\right)=(B+A)^{-1}(0), \quad \forall r>0 .
$$

Lemma 1.2 ([6]). Let $\mathrm{E}$ be a real uniformly convex Banach space and let $\mathrm{C}$ be a nonempty closed convex and bounded subset of $\mathrm{E}$. Then there is a strictly increasing and continuous convex function $\psi:[0, \infty) \rightarrow[0, \infty)$ with $\varphi(0)=0$ such that, for every Lipschitzian continuous mapping $\mathrm{T}: \mathrm{C} \rightarrow \mathrm{C}$ and, for all $\mathrm{x}, \mathrm{y} \in \mathrm{C}$ and $\mathrm{t} \in[0,1]$, the following inequality holds: $\mathrm{L} \psi^{-1}\left(\|x-y\|-\mathrm{L}^{-1}\|\mathrm{~T} x-\mathrm{T} y\|\right) \geqslant\|\mathrm{T}(\mathrm{t} x+(1-\mathrm{t}) \mathrm{y})-(\mathrm{tT} x+(1-\mathrm{t}) \mathrm{Ty})\|$, where $\mathrm{L} \geqslant 1$ is the Lipschitz constant of $\mathrm{T}$.

Lemma 1.3 ([23]). Let $\mathrm{E}$ be a real 2-uniformly smooth Banach space. Then the following inequalities hold: $\|x\|^{2}+$ $2\langle y, \mathfrak{J}(x+y)\rangle \geqslant\|x+y\|^{2}$ and $\|x\|^{2}+2\langle y, \mathfrak{J}(x)\rangle+K\|y\|^{2} \geqslant\|x+y\|^{2}, \forall x, y \in E$, where $\mathrm{K}$ is some fixed positive constant.

Lemma 1.4 ([5]). Let $\mathrm{E}$ be a real uniformly convex Banach space, $\mathrm{C}$ a nonempty closed and convex subset of $\mathrm{E}$, and $\mathrm{T}: \mathrm{C} \rightarrow \mathrm{C}$ a nonexpansive mapping. Then $\mathrm{I}-\mathrm{T}$ is demiclosed at zero, that is, $(\mathrm{I}-\mathrm{T}) \mathrm{x}_{\mathrm{n}} \rightarrow 0$ as $\mathrm{n} \rightarrow \infty$ and $\mathrm{x}_{\mathrm{n}} \rightarrow \mathrm{k}$ implies $(\mathrm{I}-\mathrm{T}) \mathrm{k}=0$.

Lemma 1.5 ([23]). Let $p>1$ and $r>0$ be two fixed real numbers. Then a Banach space $\mathrm{E}$ is uniformly convex if and only if there exists a continuous strictly increasing convex function $\varphi:[0, \infty) \rightarrow[0, \infty)$ with $\varphi(0)=0$ such that

$$
\|a x+(1-a) y\|^{p} \leqslant a\|x\|^{p}+(1-a)\|y\|^{p}-\left(a^{p}(1-a)+(1-a)^{p} a\right) \varphi(\|x-y\|),
$$

for all $x, y \in B_{r}(0):=\{x \in E:\|x\| \leqslant r\}$ and $a \in[0,1]$. In particular, we have the following

$$
\|a x+(1-a) y\|^{2} \leqslant a\|x\|^{2}+(1-a)\|y\|^{p}-a(1-a) \varphi(\|x-y\|) .
$$

Lemma 1.6 ([12]). Let $\mathrm{E}$ be a real uniformly convex Banach space such that its dual $\mathrm{E}^{*}$ has the Kadec-Klee property. Suppose that $\left\{x_{n}\right\}$ is a bounded sequence such that $\lim _{n \rightarrow \infty}\left\|a x_{n}-p_{2}+(1-a) p_{1}\right\|$ exists for all $a \in[0,1]$ and $p_{1}, p_{2} \in \omega_{w}\left(x_{n}\right)$, where $\omega_{w}\left(x_{n}\right)=\left\{x: \exists x_{n_{i}} \rightarrow x\right\}$ denotes the weak w-limit set of $\left\{x_{n}\right\}$. Then $\omega_{w}\left(x_{n}\right)$ is a singleton.

\section{Main results}

Theorem 2.1. Let $\mathrm{E}$ be a real uniformly convex and 2-uniformly smooth Banach space with constant $\mathrm{K}$. Let $\mathrm{B}: \mathrm{D}(\mathrm{B}) \subset \mathrm{E} \rightarrow 2^{\mathrm{E}}$ be an $\mathrm{m}$-accretive operator, $\mathrm{A}: \mathrm{E} \rightarrow \mathrm{E}$ an $\alpha$-inverse strongly accretive operator, and $\mathrm{T}: \mathrm{E} \rightarrow \mathrm{E}$ a nonexpansive mapping such that $(B+A)^{-1}(0) \cap \operatorname{Fix}(T) \neq \emptyset$. Let $\left\{r_{n}\right\}$ be a positive number sequence and let $\left\{\alpha_{n}\right\}$ be a real number sequence in $(0,1)$ such that $\left\{\alpha_{n}\right\} \subset[\alpha, \bar{\alpha}]$, where $\alpha$ and $\bar{\alpha}$ are two constants in $(0,1)$ and $\left\{r_{n}\right\} \subset[r, \bar{r}]$, where $r$ and $\bar{r}$ are two constants in $\left(0, \frac{2 \alpha}{K}\right)$. Let $\left\{x_{n}\right\}$ be a sequence generated in the following manner: $x_{0} \in E$ and $x_{n+1}=T\left(I+r_{n} B\right)^{-1}\left(x_{n}-r_{n} A x_{n}\right)+\alpha_{n}\left(x_{n}-T\left(I+r_{n} B\right)^{-1}\left(x_{n}-r_{n} A x_{n}\right)\right), \forall n \geqslant 0$, then $\left\{x_{n}\right\}$ converges weakly to some point in $(\mathrm{A}+\mathrm{B})^{-1}(0) \cap \operatorname{Fix}(\mathrm{T})$. 
Proof. Using Lemma 1.3, we have

$$
\begin{aligned}
\left\|\left(I-r_{n} A\right) x-\left(I-r_{n} A\right) y\right\|^{2} & \leqslant K r_{n}^{2}\|A x-A y\|^{2}-2 r_{n}\langle A x-A y, \mathfrak{J}(x-y)\rangle+\|x-y\|^{2} \\
& \leqslant K r_{n}^{2}\|A x-A y\|^{2}-2 r_{n} \alpha\|A x-A y\|^{2}+\|x-y\|^{2} \\
& =\left(K r_{n}-2 \alpha\right) r_{n}\|A x-A y\|^{2}+\|x-y\|^{2} .
\end{aligned}
$$

Since $0<r \leqslant r_{n} \leqslant \bar{r}<\frac{2 \alpha}{K}$, we find that $I-r_{n} A$ is a nonexpansive mapping. Set $J_{r_{n}}^{B}=\left(I+r_{n} B\right)^{-1}$ and fix $p \in(A+B)^{-1}(0) \cap \operatorname{Fix}(T)$. By using Lemma 1.1, we see that

$$
\begin{aligned}
\left\|x_{n+1}-p\right\| & \leqslant \alpha_{n}\left\|x_{n}-p\right\|+\left(1-\alpha_{n}\right)\left\|T J_{r_{n}}^{B}\left(x_{n}-r_{n} A x_{n}\right)-T_{r_{n}}^{B}\left(p-r_{n} A p\right)\right\| \\
& \leqslant\left(1-\alpha_{n}\right)\left\|J_{r_{n}}^{B}\left(x_{n}-r_{n} A x_{n}\right)-J_{r_{n}}^{B}\left(p-r_{n} A p\right)\right\|+\alpha_{n}\left\|x_{n}-p\right\| \\
& \leqslant\left(1-\alpha_{n}\right)\left\|\left(x_{n}-r_{n} A x_{n}\right)-\left(p-r_{n} A p\right)\right\|+\alpha_{n}\left\|x_{n}-p\right\| \\
& \leqslant\left\|x_{n}-p\right\| .
\end{aligned}
$$

It follows that $\lim _{n \rightarrow \infty}\left\|x_{n}-p\right\|$ exists, in particular, $\left\{x_{n}\right\}$ is a bounded sequence. Note that $B$ is an m-accretive operator. Setting $y_{n}=J_{r_{n}}^{B}\left(x_{n}-r_{n} A x_{n}\right)$, we find from Lemma 1.5 that

$$
\begin{aligned}
4\left\|y_{n}-p\right\|^{2} \leqslant & 4\left\|y_{n}+\frac{r_{n}}{2}\left(\frac{x_{n}-r_{n} A x_{n}-y_{n}}{r_{n}}-\frac{\left(I-r_{n} A\right) p-p}{r_{n}}\right)-p\right\|^{2} \\
= & 2\left\|y_{n}+\left(\left(I-r_{n} A\right) x_{n}-\left(I-r_{n} A\right) p\right)-p\right\|^{2} \\
\leqslant & 2\left(\left\|y_{n}-p\right\|^{2}+\left\|\left(I-r_{n} A\right) x_{n}-\left(I-r_{n} A\right) p\right\|^{2}\right. \\
& \left.-\frac{1}{2} \varphi\left(\left\|\left(y_{n}-p\right)-\left(\left(I-r_{n} A\right) x_{n}-\left(I-r_{n} A\right) p\right)\right\|\right)\right) \\
\leqslant & 4\left\|\left(I-r_{n} A\right) x_{n}-\left(I-r_{n} A\right) p\right\|^{2} \\
& -\varphi\left(\left\|\left(y_{n}-p\right)-\left(\left(I-r_{n} A\right) x_{n} n-\left(I-r_{n} A\right) p\right)\right\|\right) \\
\leqslant & 4\left(K r_{n}-2 \alpha\right) r_{n}\left\|A x_{n}-A p\right\|^{2}+4\left\|x_{n}-p\right\|^{2} \\
& -\varphi\left(\left\|\left(y_{n}-p\right)-\left(\left(I-r_{n} A\right) x_{n}-\left(I-r_{n} A\right) p\right)\right\|\right) .
\end{aligned}
$$

Since $\|\cdot\|^{2}$ is a convex function, we find from (2.1) and (2.2) that

$$
\begin{aligned}
4\left\|x_{n+1}-p\right\|^{2} \leqslant & 4 \alpha_{n}\left\|x_{n}-p\right\|^{2}+4\left(1-\alpha_{n}\right)\left\|T y_{n}-p\right\|^{2} \\
\leqslant & 4 \alpha_{n}\left\|x_{n}-p\right\|^{2}+4\left(1-\alpha_{n}\right)\left\|y_{n}-p\right\|^{2} \\
\leqslant & 4 r_{n}\left(1-\alpha_{n}\right)\left(K r_{n}-2 \alpha\right)\left\|A x_{n}-A p\right\|^{2}+4\left\|x_{n}-p\right\|^{2} \\
& -\left(1-\alpha_{n}\right) \varphi\left(\left\|\left(y_{n}-p\right)-\left(\left(I-r_{n} A\right) x_{n}-\left(I-r_{n} A\right) p\right)\right\|\right) .
\end{aligned}
$$

Since $0<r \leqslant r_{n} \leqslant \bar{r}<\frac{2 \alpha}{K}$ and $0<\alpha \leqslant \alpha_{n} \leqslant \bar{\alpha}<1$, we find that

$$
\lim _{n \rightarrow \infty}\left\|\left(y_{n}-x_{n}\right)-r_{n}\left(A p-A x_{n}\right)\right\|=0
$$

and

$$
\lim _{n \rightarrow \infty}\left\|A x_{n}-A p\right\|=0
$$

From (2.3) and (2.4) and the fact that

$$
\left\|y_{n}-x_{n}\right\| \leqslant\left\|\left(r_{n} A p-r_{n} A x_{n}\right)-\left(y_{n}-x_{n}\right)\right\|+\left\|r_{n} A p-r_{n} A x_{n}\right\|,
$$

we have

$$
\lim _{n \rightarrow \infty}\left\|x_{n}-J_{r_{n}}^{B}\left(x_{n}-r_{n} A x_{n}\right)\right\|=0 .
$$


Since $B$ is an m-accretive operator, we have

$$
\left\langle\mathfrak{J}\left(J_{r}^{B}(I-r A) x_{n}-J_{r_{n}}^{B}\left(I-r_{n} A\right) x_{n}\right), \frac{x_{n}-J_{r}^{B}(I-r A) x_{n}}{r}-\frac{x_{n}-J_{r_{n}}^{B}\left(I-r_{n} A\right) x_{n}}{r_{n}}\right\rangle \geqslant 0 .
$$

It follows that

$$
\begin{aligned}
r_{n}\left\|J_{r}^{B}(I-r A) x_{n}-J_{r_{n}}^{B}\left(I-r_{n} A\right) x_{n}\right\|^{2} & \leqslant\left(r_{n}-r\right)\left\langle x_{n}-J_{r_{n}}^{B}\left(I-r_{n} A\right) x_{n}, \mathfrak{J}\left(J_{r}^{B}(I-r A) x_{n}-J_{r_{n}}^{B}\left(I-r_{n} A\right) x_{n}\right)\right\rangle \\
& \leqslant r_{n}\left\|x_{n}-J_{r_{n}}^{B}\left(I-r_{n} A\right) x_{n}\right\|\left\|J_{r}^{B}(I-r A) x_{n}-J_{r_{n}}^{B}\left(I-r_{n} A\right) x_{n}\right\| .
\end{aligned}
$$

Therefore, we have

$$
\left\|J_{r}^{B}(I-r A) x_{n}-J_{r_{n}}^{B}\left(I-r_{n} A\right) y_{n}\right\| \leqslant\left\|x_{n}-J_{r_{n}}^{B}\left(I-r_{n} A\right) x_{n}\right\| .
$$

Following (2.5), one arrives at

$$
\lim _{n \rightarrow \infty}\left\|J_{r}^{B}\left(x_{n}-r A x_{n}\right)-x_{n}\right\|=0 .
$$

On the other hand, we have from Lemma 1.5 that

$$
\begin{aligned}
\left\|x_{n+1}-p\right\|^{2} & \leqslant\left(1-\alpha_{n}\right)\left\|T y_{n}-p\right\|^{2}+\alpha_{n}\left\|x_{n}-p\right\|^{2}+\alpha_{n}\left(\alpha_{n}-1\right) \varphi\left(\left\|T y_{n}-x_{n}\right\|\right) \\
& \leqslant\left(1-\alpha_{n}\right)\left\|y_{n}-p\right\|^{2}+\alpha_{n}\left\|x_{n}-p\right\|^{2}+\alpha_{n}\left(\alpha_{n}-1\right) \varphi\left(\left\|T y_{n}-x_{n}\right\|\right) \\
& \leqslant \alpha_{n}\left(\alpha_{n}-1\right) \varphi\left(\left\|x_{n}-T y_{n}\right\|\right)+\left\|x_{n}-p\right\|^{2} .
\end{aligned}
$$

Hence, we have

$$
\begin{aligned}
\left(1-\alpha_{n}\right) \alpha_{n} \varphi\left(\left\|x_{n}-T y_{n}\right\|\right) & \leqslant\left(\left\|x_{n}-p\right\|+\left\|x_{n+1}-p\right\|\right)\left(\left\|x_{n}-p\right\|-\left\|x_{n+1}-p\right\|\right) \\
& \leqslant M\left(\left\|x_{n}-p\right\|-\left\|x_{n+1}-p\right\|\right),
\end{aligned}
$$

where $M$ is an appropriate constant such that $M \geqslant \sup _{n \geqslant 1}\left\{\left\|x_{n}-p\right\|+\left\|x_{n+1}-p\right\|\right\}$. Since the limit of $\left\{\left\|x_{n+1}-p\right\|\right\}$ exists, we obtain that

$$
\lim _{n \rightarrow \infty}\left\|x_{n}-T y_{n}\right\|=0
$$

Note that

$$
\left\|T x_{n}-T y_{n}\right\|+\left\|T y_{n}-x_{n}\right\| \geqslant\left\|T x_{n}-x_{n}\right\| \geqslant 0
$$

By (2.5) and (2.6), we have

$$
\lim _{n \rightarrow \infty}\left\|x_{n}-T x_{n}\right\|=0 .
$$

From the demiclosed principal, we have $\omega_{w}\left(x_{\mathfrak{n}}\right) \subset \operatorname{Fix}\left(J_{r}^{B}(I+r A)\right) \cap \operatorname{Fix}(T)=(B+A)^{-1}(0) \cap \operatorname{Fix}(T)$.

Next, we show that $\omega_{w}\left(x_{n}\right)$ is a singleton set. This shows that $\left\{x_{n}\right\}$ converges weakly to some point in $(B+A)^{-1}(0) \cap \operatorname{Fix}(T)$. Define mappings $W_{n}: E \rightarrow E$ by $W_{n} x:=\operatorname{TJ}_{r_{n}}^{B}\left(I-r_{n} A\right) x-\alpha_{n} T_{r_{n}}^{B}\left(I-r_{n} A\right) x+\alpha_{n} x$, $\forall x \in$ C. Set

$$
W_{n, m}=W_{n+m-1} W_{n+m-2} \cdots W_{n}, \quad \forall n, m \geqslant 1 .
$$

Since $W_{n}$ is nonexpansive, we find that $W_{n, m}$ is also nonexpansive and $W_{n, m} x_{n}=x_{n+m}$. For all $t \in[0,1]$ and $n, m \geqslant 1$, put

$$
b_{n}(t)=\left\|t x_{n}+p_{1}-p_{2}-t p_{1}\right\|
$$

and

$$
c_{n, m}=\left\|W_{n, m}\left(t x_{n}+(1-t) p_{1}\right)-(1-t) p_{1}-t x_{n+m}\right\|,
$$

where $p_{1}$ and $p_{2}$ are in $(B+A)^{-1}(0) \cap \operatorname{Fix}(T)$. From Lemma 1.2, we have

$$
\begin{aligned}
\psi^{-1}\left(\left\|x_{n}-p_{1}\right\|-\left(\left\|x_{n+m}-p_{1}\right\|-\left\|p_{1}-W_{n, m} p_{1}\right\|\right)\right) & \geqslant \psi^{-1}\left(\left\|x_{n}-p_{1}\right\|-\left\|x_{n+m}-p_{1}-W_{n, m} p_{1}+p_{1}\right\|\right) \\
& =\psi^{-1}\left(\left\|x_{n}-p_{1}\right\|-\left\|W_{n, m} x_{n}-W_{n, m} p_{1}\right\|\right) \\
& \geqslant c_{n, m} \geqslant 0 .
\end{aligned}
$$


Hence, $\left\{c_{n, m}\right\}$ converges uniformly to zero as $n \rightarrow \infty$ for all $m \geqslant 1$. On the other hand, we have

$$
\begin{aligned}
b_{n+m}(t) & \leqslant\left\|p_{2}-W_{n, m}\left(t x_{n}+(1-t) p_{1}\right)\right\|+c_{n, m} \\
& \leqslant\left\|W_{n, m} p_{2}-W_{n, m}\left(t x_{n}+(1-t) p_{1}\right)\right\|+\left\|W_{n, m} p_{2}-p_{2}\right\|+c_{n, m} \\
& \leqslant b_{n}(t)+\left\|W_{n, m} p_{2}-p_{2}\right\|+c_{n, m} .
\end{aligned}
$$

Taking $\lim$ sup as $m \rightarrow \infty$ and then the $\lim \inf$ as $n \rightarrow \infty$, we find that

$$
\liminf _{n \rightarrow \infty} b_{n}(t) \geqslant \limsup _{n \rightarrow \infty} b_{n}(t) .
$$

This proves that $\lim _{n \rightarrow \infty} b_{n}(t)$ exists for any $t \in[0,1]$. This implies from Lemma 1.6 that $\omega_{w}\left(x_{n}\right)$ is a singleton set. This proves the proof.

For the sum of two accretive operators, we have the following result.

Corollary 2.2. Let $\mathrm{E}$ be a real uniformly convex and 2-uniformly smooth Banach space with constant $\mathrm{K}$. Let $\mathrm{B}: \mathrm{D}(\mathrm{B}) \subset \mathrm{E} \rightarrow 2^{\mathrm{E}}$ be an $\mathrm{m}$-accretive operator and let $\mathrm{A}: \mathrm{E} \rightarrow \mathrm{E}$ be an $\alpha$-inverse strongly accretive operator such that $(B+A)^{-1}(0) \neq \emptyset$. Let $\left\{r_{n}\right\}$ be a positive number sequence and let $\left\{\alpha_{n}\right\}$ be a real number sequence in $(0,1)$ such that $\left\{\alpha_{n}\right\} \subset[\alpha, \bar{\alpha}]$, where $\alpha$ and $\bar{\alpha}$ are two constants in $(0,1)$ and $\left\{r_{n}\right\} \subset[r, \bar{r}]$, where $r$ and $\bar{r}$ are two constants in $\left(0, \frac{2 \alpha}{\mathrm{K}}\right)$. Let $\left\{x_{n}\right\}$ be a sequence generated in the following manner: $x_{0} \in \mathrm{E}$ and $x_{n+1}=$ $\left(I+r_{n} B\right)^{-1}\left(x_{n}-r_{n} A x_{n}\right)+\alpha_{n}\left(x_{n}-\left(I+r_{n} B\right)^{-1}\left(x_{n}-r_{n} A x_{n}\right)\right), \forall n \geqslant 0$, then $\left\{x_{n}\right\}$ converges weakly to some point in $(B+A)^{-1}(0)$.

Further, we have the following result on common solutions of zero point problem of m-accretive operators and fixed point problem of nonexpansive operator.

Corollary 2.3. Let $\mathrm{E}$ be a real uniformly convex and 2-uniformly smooth Banach space with constant $\mathrm{K}$. Let $\mathrm{B}$ : $\mathrm{D}(\mathrm{B}) \subset \mathrm{E} \rightarrow 2^{\mathrm{E}}$ be an m-accretive operator, and $\mathrm{T}: \mathrm{E} \rightarrow \mathrm{E}$ a nonexpansive mapping such that $\mathrm{B}^{-1}(0) \cap \operatorname{Fix}(\mathrm{T}) \neq$ $\emptyset$. Let $\left\{r_{n}\right\}$ be a positive number sequence and let $\left\{\alpha_{n}\right\}$ be a real number sequence in $(0,1)$ such that $\left\{\alpha_{n}\right\} \subset[\alpha, \bar{\alpha}]$, where $\alpha$ and $\bar{\alpha}$ are two constants in $(0,1)$ and $\left\{r_{n}\right\} \subset[r, \bar{r}]$, where $r$ and $\bar{r}$ are two constants in $\left(0, \frac{2 \alpha}{K}\right)$. Let $\left\{x_{n}\right\}$ be a sequence generated in the following manner: $x_{0} \in E$ and $x_{n+1}=T\left(I+r_{n} B\right)^{-1} x_{n}+\alpha_{n}\left(x_{n}-T\left(I+r_{n} B\right)^{-1} x_{n}\right)$, $\forall \mathrm{n} \geqslant 0$, then $\left\{\mathrm{x}_{\mathrm{n}}\right\}$ converges weakly to some point in $\mathrm{B}^{-1}(0) \cap \operatorname{Fix}(\mathrm{T})$.

For a single m-accretive operator, we have the following result.

Corollary 2.4. Let $\mathrm{E}$ be a real uniformly convex and 2-uniformly smooth Banach space with constant $\mathrm{K}$. Let $\mathrm{B}: \mathrm{D}(\mathrm{B}) \subset \mathrm{E} \rightarrow 2^{\mathrm{E}}$ be an $\mathrm{m}$-accretive operator such that $\mathrm{B}^{-1}(0) \neq \emptyset$. Let $\left\{\mathrm{r}_{\mathrm{n}}\right\}$ be a positive number sequence and let $\left\{\alpha_{n}\right\}$ be a real number sequence in $(0,1)$ such that $\left\{\alpha_{n}\right\} \subset[\alpha, \bar{\alpha}]$, where $\alpha$ and $\bar{\alpha}$ are two constants in $(0,1)$ and $\left\{r_{n}\right\} \subset[r, \bar{r}]$, where $r$ and $\bar{r}$ are two constants in $\left(0, \frac{2 \alpha}{K}\right)$. Let $\left\{x_{n}\right\}$ be a sequence generated in the following manner: $x_{0} \in E$ and $x_{n+1}=\left(I+r_{n} B\right)^{-1} x_{n}+\alpha_{n}\left(x_{n}-\left(I+r_{n} B\right)^{-1} x_{n}\right), \forall n \geqslant 0$, then $\left\{x_{n}\right\}$ converges weakly to some point in $\mathrm{B}^{-1}(0)$.

\section{Applications}

First, we give a version of Hilbert spaces of Theorem 2.1.

Theorem 3.1. Let $\mathrm{E}$ be a real Hilbert space. Let $\mathrm{B}: \mathrm{D}(\mathrm{B}) \subset \mathrm{E} \rightarrow 2^{\mathrm{E}}$ be a maximal monotone operator, $\mathrm{A}: \mathrm{E} \rightarrow \mathrm{E}$ an $\alpha$-inverse strongly monotone operator and $\mathrm{T}: \mathrm{E} \rightarrow \mathrm{E}$ a nonexpansive mapping such that $(\mathrm{B}+\mathrm{A})^{-1}(0) \cap \operatorname{Fix}(\mathrm{T}) \neq \emptyset$. Let $\left\{r_{n}\right\}$ be a positive number sequence and let $\left\{\alpha_{n}\right\}$ be a real number sequence in $(0,1)$ such that $\left\{\alpha_{n}\right\} \subset[\alpha, \bar{\alpha}]$, where $\alpha$ and $\bar{\alpha}$ are two constants in $(0,1)$ and $\left\{r_{n}\right\} \subset[r, \bar{r}]$, where $r$ and $\bar{r}$ are two constants in $(0,2 \alpha)$. Let $\left\{x_{n}\right\}$ be a sequence generated in the following manner: $x_{0} \in E$ and $x_{n+1}=T\left(I+r_{n} B\right)^{-1}\left(x_{n}-r_{n} A x_{n}\right)+\alpha_{n}\left(x_{n}-T(I+\right.$ $\left.\left.r_{n} B\right)^{-1}\left(x_{n}-r_{n} A x_{n}\right)\right), \forall n \geqslant 0$, then $\left\{x_{n}\right\}$ converges weakly to some point in $(B+A)^{-1}(0) \cap \operatorname{Fix}(T)$. 
Proof. Note that in this case the concept of monotonicity coincides with the concept of accretivity. And every uniformly convex and 2-uniformly smooth Banach space is a Hilbert space. Setting K = 1, we obtain from Theorem 3.1 the desired conclusion.

Next, we give some results of minimization problems of proper lower and semicontinuous convex functions, and equilibrium problems, respectively.

For a lower semicontinuous convex function $\mathrm{g}: \mathrm{H} \rightarrow(-\infty, \infty]$, the subdifferential mapping $\partial \mathrm{g}$ is defined by

$$
\partial g(x)=\left\{x^{*} \in H:\left\langle y-x, x^{*}\right\rangle+g(x) \leqslant g(y), \quad \forall y \in H\right\}, \quad \forall x \in H .
$$

Rockafellar [21] proved that $\partial g$ is a maximal monotone operator and $0 \in \partial g(v)$ if and only if $g(v)=$ $\min _{x \in H} g(x)$.

Theorem 3.2. Let $\mathrm{E}$ be a real Hilbert space. Let $\mathrm{g}: \mathrm{E} \rightarrow(-\infty,+\infty]$ be a proper convex lower semicontinuous function and let $\mathrm{T}$ be a nonexpansive mapping on $\mathrm{E}$ such that $(\partial \mathrm{g})^{-1}(0) \cap \operatorname{Fix}(\mathrm{T})$ is not empty. Let $\left\{\mathrm{r}_{\mathrm{n}}\right\}$ be a positive number sequence and let $\left\{\alpha_{n}\right\}$ be a real number sequence in $(0,1)$ such that $\left\{\alpha_{n}\right\} \subset[\alpha, \bar{\alpha}]$, where $\alpha$ and $\bar{\alpha}$ are two constants in $(0,1)$ and $\left\{r_{n}\right\} \subset[r, \bar{r}]$, where $r$ and $\bar{r}$ are two constants in $(0,2 \alpha)$. Let $\left\{x_{n}\right\}$ be a sequence generated in the following manner: $x_{0} \in E$ and $x_{n+1}=T y_{n}+\alpha_{n}\left(x_{n}-T y_{n}\right), \forall n \geqslant 0$, where $y_{n}=\arg \min _{z \in H}\left\{\frac{\left\|z-x_{n}\right\|^{2}}{2 r_{n}}+g(z)\right\}$. Then $\left\{x_{n}\right\}$ converges weakly to some point in $(\partial g)^{-1}(0) \cap \operatorname{Fix}(T)$.

Proof. Since $\mathrm{g}: \mathrm{H} \rightarrow(-\infty, \infty]$ is a proper convex and lower semicontinuous function, we see that subdifferential $\partial \mathrm{g}$ of $\mathrm{g}$ is maximal monotone. Noting that

$$
y_{n}=\arg \min _{z \in H}\left\{g(z)+\frac{\left\|z-x_{n}\right\|^{2}}{2 r_{n}}\right\}
$$

is equivalent to

$$
\partial g\left(y_{n}\right)+\frac{1}{r_{n}}\left(y_{n}-x_{n}\right) \ni 0,
$$

it follows that

$$
y_{n}+r_{n} \partial g\left(y_{n}\right) \ni x_{n} .
$$

Putting $A=0$, we derive from Theorem 3.1 the desired conclusion immediately.

Finally, we consider the problem of finding a solution of an equilibrium problem in the terminology of Blum and Oettli [4].

Let $C$ be a closed and convex subset of $E$ and $F$ be a bifunction of $C \times C$ into $\mathbb{R}$, where $\mathbb{R}$ denotes the set of real numbers. Recall the following equilibrium problem:

$$
\text { Find } x \in C \text { such that } F(x, y) \geqslant 0, \quad \forall y \in C \text {. }
$$

The solution set of the problem is denoted by $\mathrm{Sol}(\mathrm{F})$ in this section.

To study the equilibrium problem, we need to assume that $F$ satisfies the following conditions:

(i) $F(x, y)+F(y, x) \leqslant 0, \quad \forall x, y \in C$;

(ii) for each $x \in C, y \mapsto F(x, y)$ is lower semi-continuous and convex;

(iii) $F(x, y) \geqslant \limsup _{t \rightarrow 0} F(t z+(1-t) x, y), \forall x, y, z \in C$, where $t \in(0,1)$;

(iv) $\mathrm{F}(\mathrm{x}, \mathrm{x})=0, \forall x \in \mathrm{C}$.

We remark here that $F$ is said to be monotone iff $F(x, y)+F(y, x) \leqslant 0$ for all $x, y \in C . y \mapsto F(x, y)$ is convex iff $F(t x+(1-t) y, z) \leqslant t F(x, z)+(1-t) F(y, z)$ for all $x, y, z \in C$ and $t \in(0,1) \cdot y \mapsto F(x, y)$ is lower semi-continuous iff $F\left(x, y_{n}\right) \rightarrow F(x, y)$ whenever $y_{n} \rightarrow y$ as $n \rightarrow \infty$. It is known that the indicator function 
of an open set is lower semi-continuous. There are many bifunctions satisfying restrictions (i), (ii), (iii), and (iv), for example, let $E=\mathbb{R}$ and $C=[1, \infty)$ and $F(x, y)=y-x$, then $F$ satisfies the restrictions and $\operatorname{Sol}(\mathrm{F})=\{1\}$.

Lemma 3.3 ([22]). Let $\mathrm{F}: \mathrm{C} \times \mathrm{C} \rightarrow \mathbb{R}$ be a bifunction with (i), (ii), (iii), and (iv). Then, for any $\mathrm{r}>0$ and $\mathrm{x} \in \mathrm{H}$, there exists $z \in \mathrm{C}$ such that $\mathrm{rF}(z, y) \geqslant\langle z-y, z-x\rangle, \forall y \in C$. Further, define

$$
\mathrm{T}_{\mathrm{r}}^{\mathrm{F}} x=\{z \in \mathrm{C}: \operatorname{rF}(z, y) \geqslant\langle z-y, z-x\rangle, \forall y \in C\}
$$

for all $\mathrm{r}>0$ and $\mathrm{x} \in \mathrm{H}$. Then $\mathrm{T}_{\mathrm{r}}^{\mathrm{F}}$ is a single-valued (firmly) nonexpansive mapping such that $\operatorname{Fix}\left(\mathrm{T}_{\mathrm{r}}^{\mathrm{F}}\right)=\operatorname{Sol}(\mathrm{F})$ is closed and convex. Let $\mathrm{A}_{\mathrm{F}}$ be a multivalued mapping of $\mathrm{H}$ into itself defined by

$$
A_{F} X= \begin{cases}\emptyset, & x \notin C, \\ \{z \in H:\langle y-x, z\rangle \leqslant F(x, y), \forall y \in C\}, & x \in C .\end{cases}
$$

Then $A_{F}$ is a maximal monotone operator with $\mathrm{D}\left(\mathrm{A}_{\mathrm{F}}\right) \subset \mathrm{C}, \mathrm{A}_{\mathrm{F}}^{-1}(0)=\operatorname{Sol}(\mathrm{F})$, and $\mathrm{T}_{\mathrm{r}}^{\mathrm{F}} \mathrm{x}=\left(\mathrm{I}+\mathrm{r} \mathrm{A}_{\mathrm{F}}\right)^{-1} \mathrm{x}, \forall x \in$ $\mathrm{H}, \mathrm{r}>0$.

Theorem 3.4. Let $\mathrm{E}$ be a real Hilbert space. Let $\mathrm{F}: \mathrm{C} \times \mathrm{C} \rightarrow \mathbb{R}$ be a bifunction with (i), (ii), (iii), and (iv) and let $\mathrm{T}: \mathrm{C} \rightarrow \mathrm{C}$ a nonexpansive mapping such that $\mathrm{Sol}(\mathrm{F}) \cap \operatorname{Fix}(\mathrm{T})$ is not empty. Let $\left\{\mathrm{r}_{\mathrm{n}}\right\}$ be a positive number sequence and let $\left\{\alpha_{n}\right\}$ be a real number sequence in $(0,1)$ such that $\left\{\alpha_{n}\right\} \subset[\alpha, \bar{\alpha}]$, where $\alpha$ and $\bar{\alpha}$ are two constants in $(0,1)$ and $\left\{r_{n}\right\} \subset[r, \bar{r}]$, where $r$ and $\bar{r}$ are two constants in $(0,2 \alpha)$. Let $\left\{x_{n}\right\}$ be a sequence generated in the following manner: $x_{0} \in E$ and $x_{n+1}=\mathrm{TT}_{r_{n}}\left(x_{n}-r_{n} A x_{n}\right)+\alpha_{n}\left(x_{n}-T_{r_{n}}\left(x_{n}-r_{n} A x_{n}\right)\right), \forall n \geqslant 0$, then $\left\{x_{n}\right\}$ converges weakly to some point in $\operatorname{Sol}(\mathrm{F}) \cap \operatorname{Fix}(\mathrm{T})$.

Proof. Putting $A=0$ in Theorem 3.1, we find that $J_{r_{n}}^{B}=T_{r_{n}}$. By using Theorem 3.1 and Lemma 3.3, we draw the desired conclusion immediately.

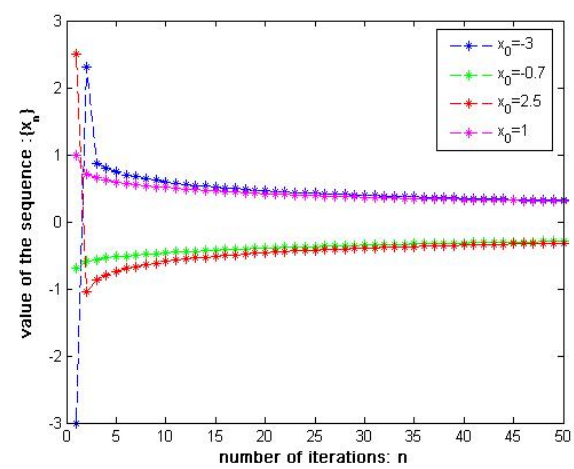

Figure 1

Finally, we give the following numerical results (using software Matlab 7.0) to illustrate the effectiveness of the algorithm in Theorem 2.1. Put $\alpha_{n}=\frac{n+e^{\frac{1}{n}}}{2 n}$. Let $E$ be the set of real numbers and $C=[-\pi, \pi]$. Let $A=x-\sin x$ and let $B$ be the subdifferential of the indicator function of $C$. Then the zero point of the sum $B$ and $A$ is 0 . If we choose $x_{0} \in C$ arbitrarily, then for 20 different initials, we see all the results are convergent in Figure 1.

\section{References}

[1] I. K. Argyros, S. George, S. M. Erappa, Expanding the applicability of the generalized Newton method for generalized equations, Commun. Optim. Theory, 2017 (2017), 12 pages. 1 
[2] B. A. Bin Dehaish, A. Latif, H. O. Bakodah, X.-L. Qin, A regularization projection algorithm for various problems with nonlinear mappings in Hilbert spaces, J. Inequal. Appl., 2015 (2015), 14 pages. 1

[3] B. A. Bin Dehaish, X.-L. Qin, A. Latif, H. O. Bakodah, Weak and strong convergence of algorithms for the sum of two accretive operators with applications, J. Nonlinear Convex Anal., 16 (2015), 1321-1336. 1

[4] E. Blum, W. Oettli, From optimization and variational inequalities to equilibrium problems, Math. Student, 63 (1994), 123-145. 3

[5] F. E. Browder, Existence and approximation of solutions of nonlinear variational inequalities, Proc. Nat. Acad. Sci. U.S.A., 56 (1966), 1080-1086. 1, 1.4

[6] R. E. Bruck, Jr., A strongly convergent iterative solution of $0 \in \mathrm{U}(\mathrm{x})$ for a maximal monotone operator $\mathrm{U}$ in Hilbert space, J. Math. Anal. Appl., 48 (1974), 114-126. 1, 1.2

[7] S. Y. Cho, B. A. Bin Dehaish, X.-L. Qin, Weak convergence of a splitting algorithm in Hilbert spaces, J. Appl. Anal. Comput., 7 (2017), 427-438. 1

[8] S. Y. Cho, X.-L. Qin, L. Wang, Strong convergence of a splitting algorithm for treating monotone operators, Fixed Point Theory Appl., 2014 (2014), 15 pages. 1

[9] P. L. Combettes, The convex feasibility problem in image recovery, Adv. Imag. Elect. Phys., 95 (1996), 155-270. 1

[10] P. L. Combettes, V. R. Wajs, Signal recovery by proximal forward-backward splitting, Multiscale Model. Simul., 4 (2005), 1168-12001

[11] N.-N. Fang, Y.-P. Gong, Viscosity iterative methods for split variational inclusion problems and fixed point problems of a nonexpansive mapping, Commun. Optim. Theory, 2016 (2016), 15 pages. 1

[12] J. García Falset, W. Kaczor, T. Kuczumow, S. Reich, Weak convergence theorems for asymptotically nonexpansive mappings and semigroups, Nonlinear Anal., 43 (2007), 377-401. 1.6

[13] S. Kamimura, W. Takahashi, Approximating solutions of maximal monotone operators in Hilbert spaces, J. Approx. Theory, 106 (2000), 226-240. 1

[14] T. Kato, Nonlinear semigroups and evolution equations, J. Math. Soc. Japan, 19 (1967), 508-520. 1

[15] S. Kitahara, W. Takahashi, Image recovery by convex combinations of sunny nonexpansive retractions, Topol. Methods Nonlinear Anal., 2 (1993), 333-342. 1

[16] N. D. Nguyen, N. Buong, An iterative method for zeros of accretive mappings in Banach spaces, J. Nonlinear Funct. Anal., 2016 (2016), 17 pages. 1

[17] X.-L. Qin, S. Y. Cho, Convergence analysis of a monotone projection algorithm in reflexive Banach spaces, Acta Math. Sci. Ser. B Engl. Ed., 37 (2017), 488-502. 1

[18] X.-L. Qin, S. Y. Cho, L. Wang, A regularization method for treating zero points of the sum of two monotone operators, Fixed Point Theory Appl., 2014 (2014), 10 pages. 1

[19] X.-L. Qin, J.-C. Yao, Weak convergence of a Mann-like algorithm for nonexpansive and accretive operators, J. Inequal. Appl., 2016 (2016), 9 pages. 1.1

[20] S. Reich, Strong convergence theorems for resolvents of accretive operators in Banach spaces, J. Math. Anal. Appl., 75 (1980), 287-292. 1

[21] R. T. Rockafellar, Augmented Lagrangians and applications of the proximal point algorithm in convex programming, Math. Oper. Res., 1 (1976), 97-116 1, 3

[22] S. Takahashi, W. Takahashi, M. Toyoda, Strong convergence theorems for maximal monotone operators with nonlinear mappings in Hilbert spaces, J. Optim. Theory Appl., 147 (2010), 27-41. 3.3

[23] H.-K. Xu, Inequalities in Banach spaces with applications, Nonlinear Anal., 16 (1991), 1127-1138. 1.3, 1.5

[24] M.-L. Zhang, Iterative algorithms for common elements in fixed point sets and zero point sets with applications, Fixed Point Theory Appl., 2012 (2012), 14 pages. 1 